Article

\title{
Recasting the Understanding of Habits for Behaviour-Oriented Policies in Transportation
}

\author{
Kevin Marechal 1,2 \\ 1 Gembloux Agro-Bio Tech-Université de Liège, B-5030 Gembloux, Belgium; k.marechal@uliege.be; \\ Tel.: +32-(0)81-622363 \\ 2 Centre for Economic and Social Studies on the Environment (CESSE-ULB), Universite Libre de \\ Bruxelles (Brussels Free University), 1050 Bruxelles, Belgium
}

Received: 28 December 2017; Accepted: 19 March 2018; Published: 21 March 2018

\begin{abstract}
The role of habits in influencing transportation behaviour is acknowledged in many studies. However, most of these analyses draw on a narrow perspective of habits. In this paper, we adopt a reversed perspective regarding the interplay between habits and rationality. The insightfulness of this perspective is illustrated with the findings of two empirical studies on urban transportation. This paper shows that the underlying structure (i.e., the "genotype") behind the phenotypic manifestation of a habit is essential to grasp for getting a better understanding of the role played by habits in explaining car use. The framework of habitual practices is then put forward in discussing the results. Its rationale is to provide a characterisation of the interconnected elements that make and shape the transportation practices, together with important aspects regarding how they are formed and sustained over time. Adequately picturing both constituent elements as well as dynamic aspects is crucial for explaining the strength of habitual practices and thus car dependence. In doing so, the framework of habitual practices could thus well be of help for policy-makers in reflecting on the design of efficient and innovative interventions for the transition towards more sustainable transportation behaviours.
\end{abstract}

Keywords: habits; practices; urban transportation; Veblenian Evolutionary Economics; car dependence

\section{Introduction}

Almost two centuries ago, Charles Darwin claimed that "(m)en are called creatures of reason, more appropriately they would be creatures of habits" [1] (p. 20, emphasis added). Resorting to habits is indeed widely recognised as a major phenomenon of social life. However, contemporary social scientists have been very reluctant to use the term "habit" [2]. Darwin's quotation may well provide one explanation: emphasising the role of habits may seem to contradict the exercise of reason and thus of intelligence. As mentioned in [3] (p. 1), beyond a broad consensus that habits and choices affect each other, "there is dispute whether habit or choice is in the driving seat". This difficulty of conceptualising the interplay between habit and reason, however, should not lead scientists to lose sight of the Darwinian imperative: the theoretical apparatus of any human science should be able to truly accommodate for the role played by habits. This is even more important in the field of transportation where behaviours "can get locked in by elements of practices which go far beyond a person's ability to exercise a rational choice" (Mattioli et al., 2016, pp. 68-69).

The role of habits has been largely acknowledged within transportation studies [4-14]. However, there are many ways to theorise habitual behaviour. In her work on urban mobilities, Middleton [15] (p. 2857) recalls that there has been "a tendency to adopt reductive conceptualisations of habits whereby habit is an external force that somehow drives human behaviour". 
In this paper, it is argued that this tendency can be mostly explained by a misleading ontological positioning regarding the articulation of habits and rationality. In contrast with traditional accounts, this paper thus starts from adopting a reversed perspective regarding the interplay between habits and rationality [16]. As explained more thoroughly elsewhere [12,13,17], this perspective is grounded on the theoretical framework of Veblenian Evolutionary Economics (VEE).

The approach to human behaviour within this framework is essentially characterised by the analytical and ontological primacy that is given to habit over choice and reason. By no means, however, does this amount to negating the role of reason. Habitual action is better viewed as the necessary foundation of rationality [18] (p. 653) and "when its relation to reflective thinking is rightly understood, it turns out to support reflection, not hinder it" [19] (p. 46). The driving rationale of this paper is to show how such a perspective leads to reconsidering the role played by habits in influencing transportation behaviours and, consequently, the many related empirical insights. This allows for a finer understanding of the dynamics at play and should thus increase the ability of policy-makers in the field to conceive more appropriate ways of modifying them.

This paper is structured as follows. Section 2 presents the main aspects of the theoretical framework that founds our work. Section 3 discusses the implications of adopting a VEE perspective for analysing the issue of urban transportation through presenting the results of two empirical studies described elsewhere $[12,13]$. Section 4 then builds on those insights to provide a discussion centred on the notion of habitual practices. Section 5 concludes the paper.

\section{Theoretical Background}

Although no social scientist would deny the existence of habits, the acknowledged extent of their pervasiveness (and thus the place they should be warranted in analyses) is not equivalent in all perspectives on human behaviour. Ascribing too much importance to habits is perceived by many as downplaying the importance of reason. However, as already stressed in the Introduction, an ex-ante imperative for accommodating the importance of habituality without discarding the existence of human intelligence is to view the former as a sine qua non condition for the latter (as theorised by William James in 1890 in his well-known book "Principles of Psychology"). Although potentially disturbing for many, this ontological "reversal" is nonetheless essential, as will be shown in the remainder of the text.

With this core idea in mind, the conceptual framework that is mobilised in this paper for approaching transportation behaviour is that of Veblenian Evolutionary Economics (VEE). Obviously, this framework is greatly inspired by the writings of Thorstein Veblen but also is indebted to his latter readers such as Geoffrey Hodgson, Olivier Brette and Erki Kilpinen. Besides Darwinian ideas, the VEE perspective also draws on contributions from pragmatist philosophers and psychologists such as William James, John Dewey or Charles Sanders Peirce. To appropriately characterise the essence of this VEE perspective on human behaviour, it is necessary to point out two fundamental features which can be subsumed by the notions of continuity and propensity.

Following Gronow's analysis [20] (p. 361), an essential aspect of Veblen's view of human behaviour is that, in sharp contrast to the utilitarian approach, it consists of a succession of actions where the "motives do not precede action because they enter the scene in the middle of ongoing action processes". Indeed, for Veblen, "the activity is itself the substantial fact of the process ( ... )" which leads him to see the human being as "a coherent structure of propensities and habits which seeks realisation and expression in an unfolding activity" [21] (pp. 390-391). This continuity of action is essential within the VEE framework as it sets the scene for the reversed perspective to rationality (as well as for the mutual interplay of habits and institutions).

The term habit is used to underline this idea of an already ongoing flow, even though a reflective view of habits could then appear as a contradiction in terms. However, it is precisely the quasi-automatic and autonomous conduct of habitual action that allows the exercise of intelligence. The rationale is that through diminishing "the conscious attention with which our acts are 
performed" [22] (p. 114), a habit releases cognitive resources that can be devoted to the performance of non-habitual type of tasks.

This cognitive efficiency of habits has been acknowledged within different streams of the literature on habits. For instance, the notion of efficiency does indeed constitute one of the "four horsemen" of automaticity as explained by Bargh [23], a major source of inspiration for the work of Bas Verplanken and Wendy Wood [24], two authorities on habits within social psychology. However, the pragmatist view on this is that, through founding their perspective on the idea of continuity, habits are viewed as "positively correlated" or "even fused" with rationality [25] (p. 1). Habitual and intelligent aspects interact during the performance of action which means that humans can be seen as endowed not only with habitual intelligence but also with intelligent habits. As already mentioned, the traditional view of rationality is thus reversed as "[i]ts role is to hinder rather than further our action process" [25] (p. 2), and, therefore, "[i]t is no more action that needs to be explained, it rather is a change in action that demands an explanation" [25] (p. 4).

This distinct perspective on the interplay between habits and rationality quite naturally takes us to the second feature of VEE, the notion of propensity. From the above discussion on intelligence, habits cannot be characterised as "mere dead routines" [20] (p. 364). Rather, they contain, in their encoding of the corresponding behaviour, the material that allows for the individual to make judgement about the habits upon which he acts. This can be illustrated with the following quotation from Thorstein Veblen: "Like other species, he is a creature of habit and propensity. But in a higher degree than other species, man mentally digests the content of habits under whose guidance he acts, and appreciates the trend of these habits. He is in an eminent sense an intelligent agent" [26] (p. 188). Following the argument developed in [18] (p. 652), in VEE, habits must thus be analysed as a propensity to behave. It follows that habits are not only more than the mere repetition of past behaviour (as already emphasised in [27]) but they also are more than the actual behaviour itself (see also [28], (p. 546)). They consist of the underlying structure which, upon favourable contextual signals, triggers the corresponding behaviour. The habit continues to exist even when the habitual action is stopped. Confusing a propensity to behave with the behaviour per se amounts to conflating genotype and phenotype in biology. Metaphorically, the action performed thus constitutes the phenotypic manifestation, in a favourable context, of the genotypic propensity that is the habit.

Although we are more inclined to describe our perspective on habits, it might be useful for the readers to provide a tentative definition summarising the many elements raised in the preceding paragraphs. Borrowing notably from Hodgson [3], a habit could then be defined as an acquired (i.e., through the continuous process of human activity) propensity to implement certain modes of action and/or thought upon encountering specific situations.

Regarding the use of the term propensity, our intention is first and foremost to underline the necessity to enlarge the perspective for it to include not only the habitual action (as it is too often the case) but also its underlying structure. This is shown in Section 3.2 to be of a great importance for the issue of urban transportation. Of a particular relevance, there is the idea that contextual policies (i.e., thus only targeting the phenotypic manifestation) are most likely doomed to fail in modifying ingrained transportation habits in the long run.

Altogether, the perspective on habits as developed within VEE is radically distinct from the approach of habits as commonly understood in many analyses. For instance, the continuity hypothesis suggests that it is not useful to study human action as a succession of discrete events, each with their attached motives [20] (p. 361). Continuity does indeed imply path-dependence [29]. In opposition to what happens in a sequentially-correlated process (see, for instance, [30], (pp. 327-328)) where habits are merely the results of a past-dependent process, the outcome of a path-dependent process cannot be defined a priori. Instead, it results from the endogenous evolution within a recursive process, under the form of self-reinforcing and circular interactions between the different elements (both at the level of individuals and of wider structures) from the system in consideration (see [16] for a more detailed 
discussion). This is of major importance in transportation where path-dependence and sociotechnical lock-in processes may well explain the low effectiveness of policies in modifying practices [11,31].

As far as the role of habits in transportation is concerned, the elements raised above would lead us to move away from considering habits as "a nuisance without which we would be better off" given that they "might also contain some resources for the treatment of the problem" [19] (p. 47). This would require, as a first step, an enrichment of our understanding of the precise role played by habits. However, prior to exposing how the VEE framework can provide an insightful perspective for understanding the dynamics at play in transportation behaviours, it is essential to emphasise that many of the pragmatist ideas that were formulated more than a century ago are being reaffirmed currently by different scientists who reached similar conclusions albeit through empirical means (see [19,32] for a good overview of the revival of those ideas based on empirical studies).

More specifically, VEE ideas are quite compatible with recent developments in cognitive sciences and related empirical evidence. Among these, there is the widely accepted work from the neurologist Antonio Damasio [33]. His study of patients with brain damage provides empirical evidence that there does not exist a clear division between automatic and controlled processes and that both overlap in producing the complex range of human behaviour. This is also corroborated by studies in neuroeconomics which claim that that "human behaviour requires a fluid interaction between controlled and automatic processes and between cognitive and affective systems ( ... ) since we see only the top of the automatic iceberg, we naturally tend to exaggerate the importance of control" [34] (p. 11).

Even more importantly, Antonio Damasio also embraces the idea of action as the main driver for the existence (and degree of use) of a mind in claiming that "(s)ome organisms have both behaviour and cognition. Some have intelligent actions but no mind. No organism seems to have mind but no action." [33] (p. 90). This leads some authors in what is referred to as embodied cognitive science to add that "only a being with habits could have a mind like ours" [35] (p. 97).

\section{Results: Using the VEE Framework to Explore Habits in Urban Transportation}

Ever since the study published by [36], urban transportation (and most notably the issue of urban commuting) has been widely studied by those researchers grounding their approach on the concept of habits (see, for instance, $[4-7,9,10]$ and also [37] for a good introduction to the many issues raised by this field of research). As emphasized by social psychologists, one reason explaining the important role played by habits in influencing commuting behaviours is that many of the trips made are characterized by both repetition and context stability. As it has been well documented in [38], such circumstances set a favourable breeding ground for habits to develop. The main insight that is raised in this perspective is that, once acquired in such a context, the habit becomes a strong predictor of behaviour "over and above intentions" [7] (p. 246). Beyond suggesting that habitual behaviour is activated without much deliberation and thought and is difficult to change, the view of habits in the realm of social psychology is thus to consider them as a moderating factor of the relation between intention and behaviour. Having strong habits can thus turn out to be a major obstacle to behaviour change even when intended [39].

Although the perspective on habits developed within social psychology shows some common aspects with VEE (see the discussion in [40]), its ontological positioning is not the same since behaviour is still primarily caused by intentions (i.e., themselves based on expected utilities). By no means does this lead us to simply discard the work performed within this discipline. Our aim is rather to complement the rich amount of empirical evidence as well as to enlarge the perspective in order to glean new type of insights.

\subsection{Habit Strength and the Extent of Effort Required}

A first way to do so is to adopt a fresh approach for analysing empirical evidence on habits gathered by social psychologists and propose a complementary interpretation. In this respect, one of the most authoritative formalisations of habit strength is the Self-Report Habit Index (SRHI) proposed 
in [41] for empirical purposes (this index has been shown to be relevant and consistent in depicting habit strength in various fields such as buying on impulse, fish consumption, adolescent nutrition, active transportation, binge drinking, physical exercise, etc. [27,42-46]). This index is used to measure self-reported perceptions of habit strength for an identified behaviour. The rationale of the SHRI is to touch upon people's meta-awareness through asking more concrete questions and breaking down the concept of habits "into components that seem easy to reflect on" [41] (p. 1325). Building in great part on the "four horsemen of automaticity" [23], these components aim to capture some characteristics of habits among which, the lack of awareness, the lack of control (i.e., changing is effortful), the increased efficiency (i.e., the fact of economizing on cognitive resources), the sense of identity and repetition (see Table 1).

The study we performed (and that is described more extensively in [13]) thus builds on this SRHI construct with the aim of complementing it with a different understanding of the precise role habits play in influencing transportation behaviours. It is a descriptive analysis of a set of data coming from an empirical survey. This survey took place alongside a small-scale intervention, whereby recent movers in two districts of Brussels (Belgium) received an informative welcome pack coupled to a conditional allocation of free public transport tickets. The design of the survey draws on earlier studies which have shown that relocation may provide a window of opportunity for a given measure to effectively induce a change of habits ([9,47-50]). This higher receptivity of recent movers towards an intervention thus constitutes a starting hypothesis for our study. This "habit discontinuity" hypothesis has been recently tested on a large sample and confirmed for a wide range of sustainable practices including a reduced car-use (see [51]).

Unsurprisingly, the results obtained within our survey confirm most of the insights already underlined in earlier analyses. For instance, the reported strength of habits is higher for commuting trips than for occasional trips (e.g., leisure, shopping, etc.), again underlining the importance of repetition and context stability. Another result is that car drivers tend to display stronger habits than users of other modes. However, this difference is only significant for occasional trips. This would tend to confirm the idea of a "once and for all" type of habit (i.e., regardless of context of use) for car drivers. Car drivers thus have a greater tendency to stick to their habitual mode in both repetitive and occasional conditions whereas users of other modes seem to display a slightly more flexible type of habit in the face of a varying context (see also the results displayed in [52] (p. 591)). Altogether, these results show (somewhat trivially) that habits do matter and that the stronger they are the stronger they matter.

As far as the intervention itself is concerned, it is also worth mentioning that it did generate its set of positive results among habitual car drivers. These results refer to a difference in the value of a given variable measured in phase 2 (i.e., about six weeks after having registered in the district) as compared to the value of the same variable in phase 1 (i.e., the day of registration). The free tickets were sent to the participants a couple of days after they had registered (see [13] for a complete description of the design of the intervention). One positive result, for instance, is that $74 \%$ of car drivers tested public transport (PT) following the provision of free tickets. In addition, the intervention triggered both a decrease in the intensity of car use and an increase in the intensity of PT use of about the same order of magnitude (i.e., a $6 \%$ variation).

However, beyond these broad results that aim at picturing the actual effectiveness of the intervention overall, it was necessary to enrich our understanding of the dynamics at play. More precisely, this required connecting the elements regarding the strength of habits and the differentiated impacts of the intervention. This is where we come back to the perspective of the present paper about the ability of the VEE framework to generate useful insights for transportation policies. Adopting a distinct perspective on habits leads to a different use of the SHRI. Its constitutive components are now viewed as "symptoms" of habits. Indeed, acknowledging the importance of the underlying structure of what is but a propensity makes it essential to analyse these "symptoms" as distinct constituents that deserve individual treatment and not only as elements that build an aggregate 
index of habit strength. This is in line with the results presented in Table 1 which show that the element "repetition" is the only one that does not seem to capture, in a statistically significant sense, any more information on the characterization of habit's strength than what is already incorporated in the generic measure.

Table 1. Values for the selected items measuring habits strength $(n=154)$.

\begin{tabular}{lcc}
\hline \multicolumn{1}{c}{ Question (i.e., Answers on A Scale Ranging from 1 to 10) } & Average Value & Difference with Generic Measure \\
\hline $\begin{array}{l}\text { Generic measure: Do you think that your daily transportation } \\
\text { behaviours are guided by habits, automatisms? }\end{array}$ & 6.68 & n.a. \\
\hline $\begin{array}{l}\text { Item 1: Using your main transportation mode to commute is } \\
\text { a behaviour that reflects who you are? }\end{array}$ & 5.58 & significant \\
\hline Item 2: Using your main transportation mode to commute is & $(p>0.001 ; \mathrm{t}=3.79)$ \\
\hline a behaviour that is anchored in your practice (through its repetition)? & 6.54 & significant \\
\hline $\begin{array}{l}\text { Item 3: The decision to use your main transportation mode to commute } \\
\text { is something that you make without thinking }\end{array}$ & 7.48 & $\begin{array}{c}\text { significant } \\
\text { Item 4: The decision to use your main transportation mode to commute }\end{array}$ \\
\hline $\begin{array}{l}\text { is something that you make without being fully aware? } \\
\text { Item 5: Using your main transportation mode to commute is }\end{array}$ & 5.65 & $(p<0.005 ; \mathrm{t}=3.30)$ \\
\hline $\begin{array}{l}\text { a behaviour that would be difficult to change (as it would require a lot } \\
\text { of effort)? }\end{array}$ & 5.41 & significant \\
\hline
\end{tabular}

Source: [13].

One hypothesis that follows is that these "symptoms" are likely to be impacted differently and that different extents of strength for these symptoms could imply different levels of receptivity to a context-change intervention. This is confirmed by the analysis which shows that "symptoms" do matter for understanding why the intervention is effective with some participants and not with others.

More specifically, what the results described in [13] suggest is that when a change of context is important enough to disrupt the habitual process that leads to the performance of a given behaviour, it seems that the key dimension in explaining the receptivity towards a specific measure lies in the perceived extent of effort required. When the extent of effort is not too high, the measure tends to induce car-drivers to try out public transport. Reversely, a high value regarding the effort required to change one's habit of driving seems to constitute a strong barrier to the adoption of a new behaviour (more than the average measure of habit strength). This seems intuitively sound since one could easily agree that a context change would not impact the general ability to change (i.e., without too much of an effort) as much as it does impact two other constitutive dimensions of the SHRI: low awareness and efficiency. These two latter elements are obviously more context-dependent than the former. This echoes some recent findings on travel habit formation and decay where it shown that "weakened habits alone cannot predict or explain who changed their behaviour after the relocation" [53] (p. 1100).

It follows that, for it to be successful, an intervention must be effective in surmounting the perceived extent of effort required (for changing a habit). This issue of contrasting abilities to change habits was already acknowledged in [54] (p. 108) where he mentions the "varying degrees of ease with which different habits are formed by different persons, as well as the varying degrees of reluctance with which different habits are given up".

\subsection{Car-Use Habits and the Importance of Associated Practices}

Grounding the reflection on the aforementioned idea of continuity, the perceived extent of effort required to change a car-use habit may be explained by this habit having become an integrant part of someone's life (i.e., in that it sustains a myriad of related practices). This was also underlined by Veblen who associated the difficulty of changing a habit with that habit being "intimately bound up with life history" [54] (p. 108).

The existence of a car-based complex of related practices makes it necessary to take into account not only the main habits associated within "trip-chaining" (e.g., taking the children to schools, grocery 
shopping, etc. (see [55])) but also seemingly less important synchronic habits (i.e., associated actions performed while driving). Taken together these synchronic habits—such as listening to the morning news while being stuck in peak traffic-may play a significant role in shaping people's convictions and behaviours. In doing so, they reinforce the strength of the central habit to which they are connected and contribute to lower the perception that the given habit can be changed without too much of an effort. This barrier may thus well be a strong explanatory factor of the differentiated degree of success of the joint provision of a welcome pack and free tickets for public transport that has been tested in the study described in Section 3.1.

Elaborating on this set of insights, it is essential to go further into assessing the empirical interest of the VEE perspective for dealing with the issue of transport. In contrast with the study performed in [13] which uses a broadly used construct (i.e., the SRHI) in a previously tested setting (i.e., giving free tickets to recent movers), this requires conceiving the whole survey for it to provide answers to the hypotheses that ensue from adopting a VEE perspective. In other words, this means designing the study based on a radically distinct theoretical posture right from the start.

This is the rationale of the second study that is discussed in the present paper and which has been thoroughly described in [12]. It is based on a survey which took place in Lyon (France) in 2010. It consisted of a two-stage enquiry whereby qualitative data (collected with voice recorders followed by in-depth interviews of 15 car drivers) were used to inform the design and content of a subsequent questionnaire submitted to 124 car drivers living in an area with good access to efficient public transport alternatives to the car.

Grounding the design of a survey on a VEE perspective requires framing it in accordance with the distinct vision of the interplay of habits and rationality (see Section 2). It follows from this imperative that a crucial pitfall to avoid is trapping the respondents into a decision theory framework by asking questions that put them in the position of decision-makers having to explain their choices. This would indeed be somewhat inconsistent with the VEE perspective.

More specifically, this also means measuring the strength of habits in another manner than that of the SHRI since habit strength cannot be entirely reduced to the extent of automaticity (although it surely is an essential feature). As explained in [12], one way to proceed is to start from the definition of a habit provided in [3], one of the most important scholars working on Veblen within evolutionary economics. In line with the argument developed above, the author defines a habit as "a propensity to behave [i.e., to implement specific patterns of action and/or thought] in a particular way in a particular class of situations" [3] (p. 4).

Taking this definition as a starting point together with the aforementioned result regarding the "once and for all" type of habit for car drivers, it follows that one additional dimension to assess is thus the scope of the habit. The scope of a given habit refers to the breadth of the spectrum of actions for which this specific pattern is activated. As explained in [12], it is to be contrasted from the intensity of a habit (i.e., the number of times of specific pattern is activated). Taking commuting trips as an illustration, the intensity of a car-use habit is the percentage of those trips that are performed with a car whereas the scope refers to the variety of situations (e.g., leisure trips, grocery shopping, visits, etc.) for which the car is also used.

A first important result from the survey that is valid for the whole sample is that the way people assess the time and costs of their most frequent journeys shows that their transportation behaviour does not derive from a well-informed rational economic trade-off between car use and use of public transport services. This confirms that there is more to transportation behaviour than utilitarian calculation (see also [56] (p. 2485)).

Although not really surprising, this result is nonetheless crucial for our perspective as it legitimises the search for other factors to explain the apparent inertia. Accordingly, the sample was divided into two groups based on the participants' degree of use of the car. This allows to distinguish between "almost car only" car drivers and "sometimes I use public transport" car drivers. Based on the assumption that both samples experience similar classes of situations, it means that the habits of the 
"sometimes I use public transport" car drivers could be interpreted in two (non-mutually exclusive) ways: either they use their personal cars and public transport alternately for particular types of trips (e.g., commuting) and/or they always use public transport for certain types of trips. Recalling Hodgson's definition, the differences in the strength of car-use habit between the two groups is due either to a difference of intensity and/or of scope. In our setting, "almost car only" drivers are, whatever the case, considered to have stronger car-use habits.

Elaborating on this distinction, the survey performed in [12] did generate some useful insights regarding the dynamics at play. In line with the above discussion on the importance of effort and its relation to the degree of connection with other habits, a first hypothesis that was analysed was to see whether the two groups would differ regarding synchronic habits (i.e., associated actions performed while driving). To this end, the participants were submitted a list of 13 associated behaviour for which they had to report their frequency of performance. The list originates from the exploratory stage of the survey (see [12] for more details regarding these elements). What the comparison between the two groups shows is that besides a higher (albeit not statistically significant) number of synchronic habits being performed by individuals in the "almost car only" group, there is a significant qualitative difference in the type of habits performed. More specifically, participants in the "almost car only" group tend to display more frequently synchronic habits that require more cognitive skills and dexterity (such as "phoning", "texting", etc.) as compared to associated behaviours such as "listening to music" or "enjoying the landscape" that are more frequent within the other group. If one subscribes to the idea that synchronic habits may well have an influence, this influence is thus likely to be somewhat different in both groups as the type of associated behaviours is distinct.

In close connection with this (although this connection was not totally anticipated), a central and seemingly puzzling result of the survey is that car-drivers with time-constrained schedules tend to display stronger car-use habits, while having stronger car-use habits also appears to increase the likelihood of car journeys being perceived as "pleasant". At first glance, it could be judged counterintuitive that the same individuals who report to be highly constrained in adopting the car as their main mode of transportation are also those who claim to find journeys travelled in cars to be "pleasant". However, building on prior knowledge regarding the role of habits as a factor enhancing both comfort and security [57], stronger habits can be regarded as providing both a way of handling time pressure and a mechanism to reduce the stress linked to driving. There is thus a sort of feedback process strengthening the importance of the strong car-use habits in the "almost car only" group. As our survey suggests, one way this process works is that strong habits allow cognitive resources to be devoted to the performance of a different type of synchronic habits (some of them requiring a form of dexterity) which contribute to make car journeys more pleasant. Travel experience is being shaped by those associated behaviours that render it more positive (at least in perception) thereby reinforcing the car-use habit. Finally, this strong relationship with other practices can turn out to be a major obstacle to change as they probably contribute to making individuals feel they have no choice or, more likely, that it would be very effortful for them to do otherwise (hence the importance of that dimension which has also been highlighted in [13]).

Drawing on the recursive perspective on causation between individual agency and structure which characterises the VEE framework, the above result may be interpreted as institutionally-constrained individuals (e.g., because of time pressure at work) exerting a certain degree of agency through taking advantage of a situation they feel they do not have much grip on. I have to take my car to work so I might as well make the best out of it. As illustrated, resorting to strong habits is the key mechanism to this respect. Habits are thus a key to the exercise of agency. As acknowledged in [57], habituation thus constitutes the mechanism through which "active" agents adjust their cognitive perceptions, matters of appreciation and normative judgements in coherent structures. The strength of these coherent structures may explain a puzzling result from the study performed by [53] where it is shown that an extant transport habit does not suddenly disappear (but rather gradually decay) even in the case of a change of mode. This takes us back to a central feature of the VEE perspective which distinguishes 
the genotype (i.e., the underlying structure) from its phenotypic manifestation (i.e., the habitual action per se).

\section{Discussion}

As thoroughly discussed throughout the present paper, having a better understanding of habits and their underlying mechanisms and structure is crucial for students of transportation behaviours. Although efficient in managing limited cognitive resources, habits can indeed become a strong factor of inertia which is thus essential to consider.

More particularly, the evidence discussed in this paper, provides a fresh entry point into what is usually termed "car dependence" in the literature (see [58] for a good introduction). Interestingly, in a recent analysis on car-dependent practices, Mattioli et al. [59] argue that "it is necessary to further develop a meso-level understanding of car dependence". Traditional accounts of car dependence have indeed mainly looked for explanations in either the attributes of individuals (micro) or the attributes of society (macro) whereas an intermediate level of analysis (i.e., a middle ground between agency and structure) could well shed a fresh light on this issue. The interest of the meso-level of analysis would be to account for both the structural constraints that are external to the individuals and the role of human action in sustaining the existence of structures that contribute to car dependence.

The perspective on habits as developed in this paper is well-equipped to provide the theoretical backbone of this necessary meso-level of understanding because the VEE framework is grounded on the idea that habits and wider structures "mutually constitute and condition each other" [60] (p. 404). The meso-level of analysis is indeed a key feature of the VEE framework through its concept of cumulative causation which posit habits as always interacting with broader socio-technical systems in a circular and self-reinforcing fashion. This set of ideas are recognised to have pioneered the subsequent work of Paul David on the concept of path-dependence and lock-in phenomena (see [61]).

However, in pointing to the need for a meso-level understanding, [59] have rather turned to practice theories, and notably the work of Elisabeth Shove (e.g., [62]), to build their analysis and typology of car dependence. Other authors have recently shown the interest of practice-based insights for transportation studies ([63-66].

This quite naturally takes us to the main idea we would like to put forward in this discussion: the intellectual fertility, for transportation studies, of coupling the VEE perspective of habits with insights from practice theories. Our various theoretical and empirical research on human action have led us to develop the framework of habitual practices which seeks to do just this (for more details see [17]). Although it is clearly beyond the scope of this paper, it is interesting to note that the conceptual commonality-which makes that the coupling exercise is theoretically sound to make-precisely comes from both habits (à la Veblen) and practice (à la Shove) being clearly situated on what [67] (p. 246) call the common "blind spot" of the allegedly opposed atomistic (micro) and holistic (macro) approaches which "both dismiss the implicit, tacit or unconscious layer of knowledge". Looking at human action through the lens of habitual practices allows us to tap into this "layer" where both sources of explanation can be accounted for. It should thus be relevant for understanding car dependence.

To grasp the interest of practice-based insights for understanding transportation behaviour, it is useful to turn to the path-breaking contribution from Andreas Reckwitz where he defines a practice as "a routinized type of behaviour which consists of several elements, interconnected to one another" [67] (p. 249 emphasis added). The richness of practice-based approaches precisely arises from the ensuing necessity to provide a characterisation of those interconnected elements that hold (bundles of) practices together.

The interest of turning to the insights from the theories of practices is that they echo many of the aspects that are discussed in the present paper. For instance, the continuity hypothesis resonates with practice-based accounts as expressed in [68] (p. 2491) where it is mentioned that in practice theory "instead of conceiving actions as isolated events, agency is seen as a flow of activities in an ongoing process". The link with "ongoing processes and practices" also is explicitly credited in [15] (p. 2858) 
in enabling a "productive dialogue" between theoretical writings on habits and policy-makers in transportation. Still in the field of transportation, Bissell [69] also proposes a fresh look at the interplay of habits and reflection that shares many aspects on which the framework of habitual practices is grounded. Finally, it is also important to mention Middleton [15] has come to a similar line of reasoning than that of habitual practices in rethinking the role of habits for understanding change in transportation behaviours.

Accordingly, the rationale of this coupled approach is to provide not only a more precise characterisation of the content of habitual practices and of their material, social and symbolic context of performance (i.e., through picturing the meanings and norms attached, the devices and technologies used, the actors concerned, the resources available, the competences and understanding of users, etc.) but also a picture of how of habitual practices are formed and sustained over time (i.e., describing the processes at play in the lock-in process of habits). This last aspect is of importance for enriching the content of practices with issue of temporalities, sequencing and habituation that are crucial for understanding car use [64-66]. Beyond the need to get a richer vision of the content of practices, assessing the extent of habituality remains an important factor as some practices are more car-dependent than others [59].

As demonstrated elsewhere for the case of energy (see $[17,70]$ ), the framework of habitual practices, through its distinct ontological perspective regarding the interplay of habits and rationality, provides other types of explanatory elements for the existence of a "behavioural (and socio-technical) lock-in" of household consumption practices. This paper suggests that it could also provide useful complementary insights for understanding car dependence. The evidence discussed in previous sections indeed points to important factors explaining the strength and persistence of car-use habits (e.g., associated practices and the extent of perceived effort required for changing). As mentioned, these factors force us to better understand the "genotype" of these habits and not only their phenotypic manifestation. The framework of habitual practices is precisely equipped to "unravel the ingredients" of this underlying structure of interconnected elements which helps sustain the existence of a dependence in the everyday life of the habitual practitioners of car-use.

\section{Conclusions}

The objective of this paper is to argue that the role of habits should be adequately considered by transportation scientists for understanding human behaviour. This would require a broader questioning of the perspective on rationality. To this end, we show that searching for inspiration in earlier contributions from pragmatist philosophers in a genuinely Darwinian perspective (such as it has been done more than a century ago by Thorstein Veblen) could prove insightful.

In studying the issue of urban transportation, the central idea of habits being defined as a propensity has led us to devote a specific attention to the "symptoms" of habits (i.e., beyond their sole contribution to an aggregated measure of strength). Among these "symptoms", it seems that the issue of effort plays a crucial part in explaining car-use habits as shown from the discussion of the two studies exposed in Section 3. This shows that the structure behind the phenotypic manifestation of a habit is essential to grasp for designing successful interventions aimed at changing this same habit. This means that the idea of propensity is also useful for reflecting on the long-term persistence of policy intervention. Ensuring that an intervention does result in modifying the "genotype" is indeed crucial for it to generate persistent effects. Non-structural interventions (e.g., providing incentives) run the risk of seeing the unchanged "genotype" giving rise to its previous phenotypic manifestation once the intervention is no longer effective (e.g., incentives have been removed).

Within a VEE framework, this means that the context of emergence of a habit is crucial to account for. As shown in the study from [12], associated practices feature among those elements that can contribute to shape the strength of a given habit through time (see Cass and Faulconbridge [66], who also stress the importance of associated elements to explain the difficulty of shifting mode). Further down our line of argumentation, we suggested that coupling insights from habits with aspects 
from practice theories could bring a novel perspective on how to apprehend behavioural change in transportation. In line with the above argument, the rationale of the framework of habitual practices is precisely to provide a characterisation of those interconnected elements that make and shape the habitual practice, together with important aspects regarding their formation and activation processes (path followed, temporal injunctions, contextual cues, etc.). Adequately picturing both constituent elements as well as dynamic aspects is crucial for explaining the strength of habitual practices and thus car dependence.

In doing so, the framework of habitual practices could thus well be of help for policy-makers in reflecting on the design of efficient and innovative interventions for the transition towards more sustainable transportation behaviours (see also the policy implications mentioned in $[59,63,64,66]$. However, although very promising, adopting a theoretical positioning such as the one discussed throughout this paper also entails a great deal of further (empirical) work. As underlined in [71] (p. 1427), if the problem is redefined, "other sort of data, and of enquiry, will be required". It is likely that this will necessitate modifying some habitual practices as to how transportation behaviour is to be apprehended. Let us hope that the perceived extent of effort required is not too high.

Conflicts of Interest: The author declares no conflict of interest.

\section{References}

1. Darwin, C. Notebook N: [Metaphysics and Expression (1838-1839)]; Transcribed by Kees Rookmaaker; Barett, P., Ed.; Cambridge University Press: Cambridge, UK, 1987; Available online: http:/ / darwin-online. org.uk/ (accessed on 10 October 2018).

2. Warde, A.; Southerton, D. Preamble: Social sciences and sustainable consumption. In The Habits of Consumption; Warde, A., Southerton, D., Eds.; Helsinki Collegium for Advances Studies: Helsinki, Finland, 2012; pp. 1-25. ISBN 978-952-10-7989-4.

3. Hodgson, G.M. Choice, habit and evolution. J. Evol. Econ. 2010, 20, 1-18. [CrossRef]

4. Aarts, H.; Verplanken, B.; van Knippenberg, A. Predicting behaviour from actions in the past: Repeated decision making or a matter of habit? J. Appl. Soc. Psychol. 1998, 28, 1355-1374. [CrossRef]

5. Gärling, T.; Fujii, S.; Boe, O. Empirical tests of a model of determinants of script-based driving choice. Transp. Res. F Traffic Psychol. Behav. 2001, 4, 89-102. [CrossRef]

6. Klöckner, C.A.; Matthies, E. How habits interfere with norm-directed behaviour: A normative decision-making models for travel choice. J. Environ. Psychol. 2004, 24, 319-327. [CrossRef]

7. Danner, U.N.; Aarts, H.; de Vries, N.K. Habits vs. intention in the prediction of future behaviour: The role of frequency, context stability and mental accessibility of past behavior. Br. J. Soc. Psychol. 2008, 47, 245-265. [CrossRef] [PubMed]

8. Thogersen, J.; Moller, B. Breaking car use habits: The effectiveness of a free one-month travelcard. Transportation 2008, 35, 329-345. [CrossRef]

9. Verplanken, B.; Walker, I.; Davis, A.; Jurasek, M. Context change and travel mode choice: Combing the habit discontinuity and self-activation hypotheses. J. Environ. Psychol. 2008, 28, 121-127. [CrossRef]

10. Gardner, B. Modelling motivation and habit in stable travel mode context. Transp. Res. F Traffic Psychol. Behav. 2009, 12, 68-76. [CrossRef]

11. Schwanen, T.; Banister, D.; Anable, J. Rethinking habits and their role in behaviour change: The case of low-carbon mobility. J. Transp. Geogr. 2012, 24, 522-533. [CrossRef]

12. Brette, O.; Buhler, T.; Lazaric, N.; Maréchal, K. Reconsidering the nature and effects of habits in urban transportation behavior. J. Inst. Econ. 2014, 10, 399-426. [CrossRef]

13. Maréchal, K. An in-depth analysis of the role played by habits in urban transportation: Insights from Veblenian Evolutionary Economics. J. Transp. Econ. Policy 2016, 50, 205-220.

14. Şimşekoğlu, O.; Nordfjærn, T.; Rundmo, T. Predictors of car use habit strength in an urban Norwegian public. Transportation 2017, 44, 575-588. [CrossRef]

15. Middleton, J. I'm on autopilot, I just follow the route: Exploring habits, routines, and decision-making practices of everyday urban mobilities. Environ. Plan. A 2011, 43, 2857-2877. [CrossRef] 
16. Maréchal, K. The Economics of Climate Change and the Change of Climate in Economics; Routledge: London, UK, 2012; ISBN 978-0-415-69375-2.

17. Maréchal, K.; Holzemer, L. Getting a (sustainable) grip on energy consumption: The importance of household dynamics and 'habitual practices'. Energy Res. Soc. Sci 2015, 10, 228-239. [CrossRef]

18. Hodgson, G.M. Reclaiming habit for institutional economics. J. Econ. Psychol. 2004, 2, 651-660. [CrossRef]

19. Kilpinen, E. Human beings as creatures of habit. In The Habits of Consumption; Warde, A., Southerton, D., Eds.; Helsinki Collegium for Advances Studies: Helsinki, Finland, 2012; pp. 45-69. ISBN 978-952-10-7989-4.

20. Gronow, A. Not by rules or choices alone: A pragmatist critique of institution theories in economy and sociology. J. Inst. Econ. 2008, 4, 351-373. [CrossRef]

21. Veblen, T. Why is Economics not an evolutionary science? Q. J. Econ. 1898, 12, 373-397. [CrossRef]

22. James, W. Principles of Psychology; Henry Holt and Company: New York, NY, USA, 1890; Volume 1, [1931].

23. Bargh, J.A. The four horsemen of automaticity: Awareness, intention, efficiency, and control in social cognition. In Handbook of Social Cognition; Wyer, R.S., Srull, T.K., Eds.; Lawrence Erlbaum Associates: Hillsdale, NJ, USA, 1994; pp. 1-40.

24. Verplanken, B.; Wood, W. Interventions to break and create consumer habits. J. Public Policy Mark. 2006, 25, 90-103. [CrossRef]

25. Kilpinen, E. A positive correlation between rationality and habituality-What does it mean? In Proceedings of the ISNIE Annual Conference, Barcelona, Spain, 22-24 September 2005.

26. Veblen, T. The instinct of workmanship and the irksomeness of labor. Am. J. Sociol. 1898, 4, $187-201$. [CrossRef]

27. Verplanken, B. Beyond frequency: Habits as mental construct. Br. J. Soc. Psychol. 2006, 45, 639-656. [CrossRef] [PubMed]

28. Klimina, A. Veblenian Concept of Habit and Its Relevance to the Analysis of Captured Transition. J. Econ. Issues 2008, 42, 545-552. [CrossRef]

29. Brette, O.; Lazaric, N.; Vieira, V. Habit, decision making and rationality: Comparing Thorstein Veblen and early Herbert Simon. J. Econ. Issues 2017, 51, 567-587.

30. Becker, G.S. Habits, addictions, and traditions. Kyklos 1992, 45, 327-346. [CrossRef]

31. Gössling, S.; Cohen, S. Why sustainable transport policies will fail: EU climate policy in the light of transport taboos. J. Transp. Geogr. 2014, 39, 197-207. [CrossRef]

32. Twomey, P. Reviving Veblenian Economic Psychology. Camb. J. Econ. 1998, 22, 433-448. [CrossRef]

33. Damasio, A. Descartes' Error: Emotion, Reason and the Human Brain; Putnam: New York, NY, USA, 1994; ISBN 0-380-72647-5.

34. Camerer, C.; Loewenstein, G.; Prelec, D. Neuroeconomics: How Neuroscience Can Inform Economics. J. Econ. Lit. 2005, 43, 9-64. [CrossRef]

35. Noë, A. Out of Our Heads: Why You Are Not Your Brain, and Other Lessons from the Biology of Consciousness; Hill and Wang: New York, NY, USA, 2009; ISBN 978-0-8090-7465-5.

36. Verplanken, B.; Aarts, H.; van Knippenberg, A.; van Knippenberg, C. Attitude versus general habit: Antecedents of travel mode choice. J. Appl. Soc. Psychol. 1994, 24, 285-300. [CrossRef]

37. Gärling, T.; Axhausen, K. Introduction: Habitual travel choice. Transportation 2003, 30, 1-11. [CrossRef]

38. Ouellette, J.A.; Wood, W. Habit and intention in everyday life: The multiple processes by which past behavior predicts future behavior. Psychol. Bull. 1998, 124, 54-74. [CrossRef]

39. Verplanken, B.; Faes, S. Good intentions, bad habits, and effects of forming implementation intentions on healthy eating. Eur. J. Soc. Psychol. 1999, 29, 591-604. [CrossRef]

40. Maréchal, K. An evolutionary perspective on the economics of energy consumption: The crucial role of habits. J. Econ. Issues 2009, 43, 69-88. [CrossRef]

41. Verplanken, B.; Orbell, S. Reflections on past behaviour: A self-report index of habit strength. J. Appl. Soc. Psychol. 2003, 33, 1313-1330. [CrossRef]

42. De Bruijn, G.J.; Kremers, S.P.J.; Singh, A.; van den Putte, B.; Van Mechelen, W. Adult Active transportation: Adding Habit Strength to the Theory of Planned Behavior. Am. J. Prev. Med. 2009, 36, 189-194. [CrossRef] [PubMed]

43. De Bruijn, G.J.; Kremers, S.P.J.; De Vet, E.; De Nooijer, J.; Van Mechelen, W.; Brug, J. Does habit strength moderate the intention-behaviour relationship in the Theory of Planned Behaviour? The case of fruit consumption. Psychol. Health 2007, 22, 899-916. [CrossRef] 
44. Kremers, S.P.; van der Horst, K.; Brug, J. Adolescent screen-viewing behaviour is associated with consumption of sugar-sweetened beverages: The role of habit strength and perceived parental norms. Appetite 2007, 48, 345-350. [CrossRef] [PubMed]

45. Norman, P. The theory of planned behavior and binge drinking among undergraduate students: Assessing the impact of habit strength. Addict. Behav. 2001, 36, 502-507. [CrossRef] [PubMed]

46. Verplanken, B.; Melkevik, O. Predicting habit: The case of physical exercise. Psychol. Sport Exerc. 2008, 9, 15-26. [CrossRef]

47. Bamberg, S. Is a Residential Relocation a Good Opportunity to Change People's Travel Behavior? Results From a Theory-Driven Intervention Study. Environ. Behav. 2006, 38, 820-840. [CrossRef]

48. Bamberg, S. Using a residential relocation as starting point for breaking car use habits. In Proceedings of the Cases in Sustainable Consumption and Production, Workshop of the Sustainable Consumption Research Exchange (SCORE!) Network, Brussels, Belgium, 4-5 June 2007; pp. 365-374.

49. Schäfer, M.; Bamberg, S. Breaking habits: Linking sustainable consumption campaigns to sensitive events. In Proceedings of the 2008 SCORE Conference on Sustainable Consumption and Production: Framework for Action, Brussels, Belgium, 10-11 March 2008; pp. 213-228.

50. Schäfer, M.; Herde, A.; Kropp, C. Life events as turning points for sustainable nutrition. In System Innovation for Sustainability: Sustainable Consumption and Production of Food; Tischner, U., Kjærnes, U., Stø, E., Tukker, A., Eds.; Greenleaf Publishing: Sheffield, UK, 2010; pp. 210-226. ISBN 978-1906093242.

51. Verplanken, B.; Roy, D. Empowering interventions to promote sustainable lifestyles: Testing the habit discontinuity hypothesis in a field experiment. J. Environ. Psychol. 2016, 45, 127-134. [CrossRef]

52. Domarchi, C.; Tudela, A.; Gonzales, A. Effect of attitudes, habit and affective appraisal on mode choice: An application to university workers. Transportation 2008, 35, 585-599. [CrossRef]

53. Walker, I.; Thomas, G.; Verplanken, B. Old habits die hard: Travel habit formation and decay during an office relocation. Environ. Behav. 2015, 47, 1089-1106. [CrossRef]

54. Veblen, T. The Theory of the Leisure Class: An Economic Study in the Evolution of Institutions; Penguin Books: New York, NY, USA, 1899; [1994]; ISBN 978-0-14-018795-3.

55. Ye, X.; Pendyala, R.M.; Gottardi, G. An exploration of the relationship between mode choice and complexity of trip chaining patterns. Transp. Res. Part B Methodol. 2007, 41, 96-113. [CrossRef]

56. Lin, W. Wasting time? The differentiation of travel time in urban transport. Environ. Plan. A 2012, 44, 2477-2492. [CrossRef]

57. Lindbladh, E.; Lyttkens, C.H. Habit versus choice: The process of decision-making in health-related behavior. Soc. Sci. Med. 2002, 55, 451-465. [CrossRef]

58. Goodwin, P. Editorial: Car dependence. Transp. Policy 1995, 3, 151-152. [CrossRef]

59. Mattioli, G.; Anable, J.; Vrotsou, K. Car dependent practices: Findings from a sequence pattern mining study of UK time use data. Transp. Res. A Policy Pract. 2016, 89, 56-72. [CrossRef]

60. Hodgson, G.M. Economics and the return to Mecca: The recognition of novelty and emergence. Struct. Change Econ. Dyn. 1997, 8, 399-412. [CrossRef]

61. Maréchal, K. Not irrational but habitual: The importance of 'behavioural lock-in' in energy consumption. Ecol. Econ. 2010, 69, 1104-1114. [CrossRef]

62. Shove, E. Converging Conventions of Comfort, Cleanliness and Convenience. J. Consum. Policy 2003, 26, 395-418. [CrossRef]

63. Watson, M. How theories of practice can inform transition to a decarbonised transport system. J. Transp. Geogr. 2012, 24, 488-496. [CrossRef]

64. Hui, A. Moving with practices: The discontinuous, rhythmic and material mobility of leisure. Soc. Cult. Geogr. 2013, 14, 888-908. [CrossRef]

65. Kent, J. Driving to same time or saving time to drive? The enduring appeal of the private car. Transp. Res. A Policy Pract. 2014, 65, 103-115. [CrossRef]

66. Cass, N.; Faulconbridge, J. Commuting practices: New insights into modal shift from theories of social practice. Transp. Policy 2016, 45, 1-14. [CrossRef]

67. Reckwitz, A. Toward a theory of social practices: A development in culturalist theorizing. Eur. J. Soc. Theory 2002, 5, 243-263. [CrossRef]

68. Røpke, I. Theories of practice-New inspiration for ecological economic studies on consumption. Ecol. Econ. 2009, 68, 2490-2497. [CrossRef] 
69. Bissell, D. Thinking habits for uncertain subjects: Movement, stillness, susceptibility. Environ. Plan. A 2011, 43, 2649-2665. [CrossRef]

70. Maréchal, K.; Holzemer, L. Unravelling the 'ingredients' of energy consumption: Exploring home-related practices in Belgium. Energy Res. Soc. Sci 2018, 39, 19-28. [CrossRef]

71. Shove, E. Putting practice into policy: Reconfiguring questions of consumption and climate change. Contemp. Soc. Sci. J. Acad. Soc. Sci. 2014, 9, 415-429. [CrossRef] 